УДК 1; 321; 323.2

ДАХИН Андрей Васильевич - доктор философских наук, профессор кафедры истории и теории государства и права Нижегородского института управления - филиала Российской академии народного хозяйства и государственной службы при Президенте РФ (603950, Россия, г. Нижний Новгород, nр-кт Гагарина, 46; nn9222@rambler.ru)

БАЛУЕВА Ирина Владимировна - помощник депутата Городской думы Нижнего Новгорода (603006, Россия, г. Нижний Новгород, ул. Володарского, 4, каб. 398; irina_balu@таil.ru)

ДАВЫДОВ Сергей Владимирович - помощник депутата Законодательного собрания Нижегородской области, аспирант кафедры философии, социологии и психологии управления Нижегородского института управления - филиала Российской академии народного хозяйства и государственной службы при Президенте РФ (603950, Россия, г. Нижний Новгород, пр-кт Гагарина, 46; 537395@ mail.ru)

ЩЕТИНИНА Ольга Владимировна - заместитель председателя Законодательного собрания Нижегородской области, аспирант кафедры философии, социологии и психологии управления Нижегородского института управления - филиала Российской академии народного хозяйства и государственной службы при Президенте РФ (603950, Россия, г. Нижний Новгород, nр-кт Гагарина, 46; Lmakarova.zsno@yandex.ru)

\title{
СИСТЕМА ПУБЛИЧНОЙ ВЛАСТИ И РЕГИОНАЛЬНАЯ СТРАТИФИКАЦИЯ ПОЛИТИЧЕСКОГО ПРОСТРАНСТВА РОССИИ: ИНСТИТУТЫ В ПОИСКЕ СОЦИАЛЬНОГО СУБЪЕКТА
}

\begin{abstract}
Аннотация. В статье рассматриваются философские и междисциплинарные аспекты формирования единой системы публичной власти в России во взаимосвязи с вопросами региональной стратификации политического пространства. На основе комплексного анализа концептов «политический режим», «политический процесс", «потенциал государства» предлагается философия их интеграции в концептуальную рамку региональной стратификации политического пространства. На примере муниципального уровня системы публичной власти показан характер взаимосвязи названных концептов, а также возможности нового подхода к анализу роли институтов МСУ и роли социальных субъектов муниципальных территорий для становления полноценной системы муниципальной публичной власти, соотношения «вертикальных» и «горизонтальных» социально-политических отношений, исследования актуальных тенденций. $B$ заключение делается вывод о важности проработки философии связи представлений о природе единой системы публичной власти с региональной стратификацией политического пространства в России, а также отмечается необходимость проработки отечественной философии человека как субъекта цивилизационного, социального и политического развития.
\end{abstract}

Ключевые слова: единая система публичной власти, Россия, региональная стратификация политического пространства, социальный институт, социальный субъект, политический режим, потенциал государства, муниципальная публичная власть

2020 г. в число ключевых характеристик российского государства введено новое понятие - «система публичной власти». Конституционный статус понятия отражает новый этап правового оформления единой «социальной власти», которая выделена «от народа и в конституционно-правовом порядке наделена народом правом на осуществление полномочий от своего имени» [Советов 2020: 45]. Текст федерального конституционного закона № 1-ФК3 связывает систему публичной власти с вопросами управления «федеральными 
территориями», с особенностями «осуществления публичной власти на территориях городов федерального значения, административных центров (столиц) субъектов Российской Федерации и на других территориях», а также с тем, что «органы местного самоуправления и органы государственной власти входят в единую систему публичной власти в Российской Федерации» ${ }^{1}$. Эти формулировки прямо указывают на то, что понятие «единая система публичной власти» не только ставит новые рамки деятельности для федеральных органов власти, но адресует эти рамки также и всей структуре региональной стратификации политического управления в России. Несмотря на то что «понятие публичной власти давно проработано в правовой науке» [Советов 2020: 45-46], соединение принятых законов с «обычным правом - правилами, традициями, нормами реальной жизни» сопровождается конфликтами «реальной и правовой политики» [Круглый стол... 2020: 39]. Проблемное правовое поле разогревают также исследования общей ситуации противоречий, несоответствий, вызовов, антагонизмов в сфере правовой деятельности, которые определяются как кризис, признаками которого являются «юридический монизм» и фетишизация института права, иллюзия всемогущества позитивного права, блокировка обычая как источника права, избыточность и чрезвычайность национального законодательства при избирательности, «релятивизме» правоприменения [Рувинский 2020: 197-198, 205, 215, 210, 211, 222, 224, 226, 228]. Поэтому новое конституционное понятие «единая система публичной власти» не столько проясняет философию организации российской власти, сколько заостряет вопрос о необходимости ее прояснения, общественного проговаривания, сущностного смыслового уточнения. Упомянутый уже текст закона № 1-ФКЗ не дает развернутой дефиниции того, что такое «система публичной власти» в России. Он устанавливает, что единая система публичной власти - это одна из ценностей России и в этом качестве требует философского, междисциплинарного гуманитарного осмысления в соотношении с проблемой справедливости [Зорькин 2019], с проблемой «морального износа власти» [Шатилов 2020], с проблемой отечественного содержания понятий «светского» и «социального» государства [Дахин 2019] и др.

Философия единой системы публичной власти начинается с вопросов о деятельности публичной власти: «собственно властная деятельность сочетается с координирующей деятельностью в отношении тех социальных институтов, которые отличаются большей или меньшей степенью самоорганизации [Советов 2020: 46], включает «направления деятельности различных субъектов, главным образом государства и муниципальных образований, по удовлетворению публичного, то есть общественного интереса, признанного и охраняемого государством» [Жилина 2006: 7]. При этом есть необходимость прояснения того, как соотносятся «функции публичной власти» и то, что называют «публичной политикой». В русле политической науки деятельность системы публичной власти описывается понятием «публичная политика» это деятельность, в которой происходит взаимодействие институтов государства, частного сектора, гражданского общества, а также различных социальных, профессиональных групп, слоев, общественных объединений населения конкретных территорий [Михеев 2005]. Другие формулировки делают акцент на том, что публичная политика - это деятельность акторов, т.е. социальнополитических субъектов, среди которых, наряду с государством, перечисля-

1 Закон Российской Федерации о поправке к Конституции Российской Федерации от 14.03.2020 № 1-ФК3 «О совершенствовании регулирования отдельных вопросов организации и функционирования публичной власти». - Собрание законодательства РФ. 2020. № 11. Ст. 1, п. 1(а), п. 44(г), п. 45(в). 
ются различные НКО, бизнес, СМИ, научное университетское сообщество [Сунгуров 2006]. Приведенные фрагменты отражают своеобразную дилемму философии публичной власти, которая сводится к вопросу о соотношении роли институтов публичной политики и роли субъектов публичной политики в общей системе публичной власти. Институционалисты - от Дж. Гэлбрейта до Э. Остром - убеждают, что именно институты решают ключевые задачи публичной власти [Остром 2010; Глазьев 2017], к перечню которых относят обеспечение безопасности, обеспечение стандартов жизни определенного уровня, обеспечение сохранения и воспроизводства публичной власти [Советов 2020: 46]. Однако движение государственной власти по этому пути ведет к распространению патерналистских настроений в обществе, к бессубъектности и дегуманизации социальных отношений [Чепьюк 2021], а соединение социальных и политических институтов с тенденцией кибернетизации выживает человека из социума [Кутырев, Слюсарев, Хусяинов 2020].

Противоречивость ситуации обостряется установками стратегии публичной политики России, которая ориентируется на то, что патерналистское государство «политически нецелесообразно и экономически невозможно» ${ }^{1}$, что к 2024 г. требуется увеличение доли граждан, принимающих участие в решении вопросов развития городской среды, до $30 \%$ (п. 6) ${ }^{2}$. При этом исходные условия характеризуются тем, что «уровень реального политического участия российских граждан практически не растет. Как и в предыдущие годы, он составил... не более 1\% [Горшков 2016: 30]. Другими словами, существует стратегический запрос публичной политики на гражданина как субъекта муниципальной публичной политики, экономической политики, социальной политики. Запрос усиливает российская ситуация общественно-политических трансформаций, которая требует поиска «активных субъектов преобразований, способных эффективно действовать в этом ключе, а также сложностей, препятствующих их реализации» [Макаренко 2020: 158]. О том, насколько важна и сложна задача перехода граждан из состояния патерналистского ожидания помощи (государства) в состояние субъектного, активного участия в решении собственных проблем говорят практики внедрения «социального контракта», равно как и практики по правовому «обузданию» самозанятого населения. Проблема внедрения «социального контракта» сталкивается с иждивенческими настроениями, неуверенностью в собственных силах и пр., из-за чего «в большинстве регионов отмечается относительно низкий уровень конечного выхода участников программ на самообеспечение» [Прокофьева и др. 2015: 86]. Такова проблема ослабленной субъектности. Работа с самозанятым населением, напротив, связана со своеобразной гиперактивной самостоятельностью, которая никак не хочет вписываться в рамки «государственного регулирования деятельности самозанятых» [Покида, Зыбуновская 2020: 167]. Таков случай гиперсубъектности. Работа по обеим категориям сводится к тому, чтобы сформировать такое качество социального субъекта, который бы соответствовал как требованиям самообеспечения, так и требованиям государственного регулирования.

Конкретный комплексный узел вопросов взаимосвязи институциональных и субъектных элементов публичной власти и публичной политики завязался вокруг системы муниципального самоуправления. Политический транзит

1 Путин В.В. Послание Президента РФ Федеральному Собранию от 08.07.2000. Какую Россию мы строим. Доступ: http://www.consultant.ru/document/cons_doc_LAW_27823/

2 Указ Президента РФ «О национальных целях и стратегических задачах развития Российской Федерации на период до 2024 г.» от 07.05.2020. Доступ: http://kremlin.ru/events/ president/news/57425. 
института местного самоуправления характеризуется преобладанием «вертикальных связей с уровнями государственной власти» над «совершенствованием горизонтальных, сетевых», необходимостью установления «необходимого баланса» вертикальных и горизонтальных связей, где проблемы горизонтальных связей обусловлены тем, что «в России понятие местного сообщества как активного субъекта местного самоуправления до настоящего времени практически не использовалось» [Букалова, Меркулова 2020: 78]. Теоретический анализ комплекса этих вопросов усложняется тем, что в этой области исследования задействовано несколько различных концептов. Во-первых, это концепт политических режимов, который увязывает исследования с более широкой совокупностью факторов политики и понятий политической теории, но который далек от законченного совершенства. Во-вторых, он включает два ключевых элемента: 1) совокупность акторов ( a set of actors) и 2) совокупность институтов (a set of institutions) [Gel'man 2008: 158]. К этой упрощенной схеме добавляются факторы среднего уровня, в частности наследие прошлого (legacy of the past) и предшествующий опыт нации (nation's previous experience), что относят к категории факторов внутреннего происхождения (endogenous factors), которые соотносят с совокупностью внешних факторов (a set of exogenous factors), в число которых включают международную среду и экономические условия (international environment, economic conditions) [Gel'man 2008: 159-160]. Важно отметить также и то, что совокупность акторов подразумевает политические элиты, в которых выделяются перечень групп и отношения между ними и которые характеризуются доступными для них ресурсами и возможностями их мобилизации. Методология анализа политических режимов ориентирована на выявление не только элементов демократического стиля поведения, но и элементов авторитаризма. Гибридный характер систем политического правления, который выявляется в исследованиях постсоветских стран, показывает, что политические акторы по тем или иным причинам способны комбинировать различные политические механизмы. Характер такой комбинации (в этом и состоит особенность каждого конкретного политического режима), как показывает В. Гельман, развивая идеи Р. Даля [Dahl 1971: 15], резюмирует, что комбинация зависит от соотношения «цены», которую должны заплатить политические акторы, и политического «результата», который они получат [Gel'man 2008: 160-161]. Использование концепта «политический режим» в поле региональных и муниципальных исследований сопряжена с переосмыслением «нерелевантной теоретической рамки» [Гайворонский 2015: 21, 22]. В частности, Р.Ф. Туровский предлагает анализ локального политического режима в трех измерениях: «консолидация - конкуренция», «автономия - зависимость», «демократия - авторитаризм» [Туровский 2009]. К базовой конструкции политического режима профессор Туровский добавляет еще один значимый элемент - региональное гражданское общество (в т.ч. гражданские права, политическую оппозицию), с чем связаны различные дополнительные факторы среднего уровня (гражданское участие, свобода СМИ, уровень насилия и др.), а также вносит фактор, учитывающий субнациональный статус локального режима (акторы и институты федерального и регионального уровня, а также отношения между ними).

Второй элемент - это концепт политического процесса, в т.ч. базового политического процесса [Дахин, Распопов 1998]. Анализ его соотношения с понятием политического режима позволяет заключить, что специфика первого в том, что он фокусирует внимание исследователя на процессуальной, темпоральной стороне функционирования всех элементов, которые входят в концептуальную рамку политического режима (цикличность - линейность, 
прерывность - непрерывность, активность - пассивность и пр. характеристики).

Третий краеугольный концепт связан с понятием «потенциал государства» (state capacities), который работает в связке с понятием «политический режим» (региональность берется здесь в страновом формате) [Croissant, Hellman 2018]. Д. Уайт выделяет дилемму «восстановления способностей государства» и «режима репрессий» в России, поясняя, что установление вертикали власти базируется не на сильном потенциале государства, но служит консолидации режима [White 2018: 130-131]. С опорой на работу Т. Скочпол выделяются три базовые характеристики потенциала государства: а) обилие ресурсов, б) состояние административно-силового контроля на территории, в) лояльные и профессионально обученные чиновники [Skocpol 1985]. Формула соотношения понятий «политический режим» и «потенциал государства» предложена И.М. Бусыгиной. Она рассматривает государство в качестве «машины» политического управления, а «режим» - в качестве «оператора», который может менять функциональные характеристики, настройки политической машинерии. При этом полагается, что машина - это нечто более постоянное, устойчивое, глубинное, а режим - нечто более изменчивое, вре́менное, поверхностное [Busygina 2016: 74, 94].

Четвертый концепт - это региональная стратификация политического пространства и понятие «модель регионального политического управления» А.В. Дахина, в свете которых единое политическое пространство страны рассматривается разделенным на административно-территориальные политические страты (политические территории) различного калибра, где ключевыми являются: страта жилого комьюнити / микрорайон города - муниципальная страта / город - страта субъекта федерации - общегосударственная страта / страна [Дахин 2009; 2015a; 2015б]. В основе системы региональной стратификации лежит связь сообществ людей с территорией их проживания, скрепленная а) коллективными структурами идентичности, коллективной памятью аборигенного сообщества (общинная традиция); б) различного рода гражданско-правовыми отношениями (собственность на объекты недвижимости, находящиеся на данной территории, регистрация места жительства, регистрация юридического адреса бизнеса, территориальная налоговая подотчетность и пр.); в) политическими отношениями (связь с избирательным участком, с электоральными ресурсами территории, депутатский мандат конкретного органа власти муниципалитета и пр.). Поэтому региональная страта общества - это социальная территория, т.е. территория, интегрированная в коллективное жизненное пространство сообщества. Региональная страта системы публичной власти - это коллективное жизненное пространство политического сообщества, проживающего на территории. В политической сфере региональная стратификация базируется на взаимосвязи гражданских, политических сообществ с географической территорией, на которой осуществляется их политическая деятельность и на которую распространяется их политическое влияние. Содержательная взаимосвязь политического сообщества и территории его политической активности также базируется на активной идентичности и коллективной памяти [Дахин 2016], благодаря которым территория становится для политического сообщества «своей». Существенным фактором является и то, что сообществу свойственна функция субъекта политической деятельности [Дахин, Распопов 1998: 139-140]. Пределы «своих» политических территорий фиксируются границей, наиболее устойчивой формой которой является административная граница. В совокупности все названные компоненты образуют единичный 
таксон системы региональной стратификации пространства публичной власти - политический регион, т.е. задают целостное внутреннее строение единицы организации политического пространства «независимо от ее масштаба (таксономического уровня)» [Киреев 2014: 19].

Анализ триады «политический режим», «политический процесс», «потенциал государства» приводит к заключению, что все три концепта охватывают своими понятийно-методологическими сетями ключевые стороны политического региона любого таксономического уровня, в т.ч. систему публичной власти страны. Учитывая это обстоятельство и проведя сравнение перечня факторов региональной политики, связанных с триадой «региональный политический режим», «региональный политический процесс», «региональный потенциал государства», и факторов, характеризующих стандартный таксон в системе региональной стратификации системы публичной власти, мы пришли к выводу, что значительное число факторов совпадают. Это прежде всего факторы, учитывающие субъектные функции регионального сообщества (акторы, в т.ч. региональные элиты, субъекты гражданской, электоральной активности), и факторы, учитывающие функционирование региональных и иных политических институтов (в т.ч. региональные ветви власти, институт выборов, СМИ и др.). В совокупности они позволяют характеризовать систему отношений «региональное сообщество - институты региональной власти», которые развиваются в «горизонтальном» измерении и изучаются в основном в рамках концепта «региональный политический режим», и систему отношений различных общественно-политических институтов в административнотерриториальных границах региональной территории, которые развиваются преимущественно в «вертикальном» измерении и изучаются в основном в рамках концепта «потенциал государства». За скобками названных концептуальных подходов остаются в основном факторы, описывающие формы солидарности населения, отражающие их связь с конкретной территорией, хотя часть из них может учитываться в качестве факторов среднего уровня: наследия прошлого (legacy of the past) и предшествующего опыта нации (nation's previous experience) [Gel'man 2008]. Таким образом, целостный анализ региональной страты системы публичной власти любого таксономического уровня может быть достигнут с использованием концептуальной рамки «политический режим», концептуальной рамки «потенциал государств» и концептуальной рамки «региональный политический процесс» (процессуальная составляющая двух первых концепций). Собственная рамка концепта региональной стратификации политического пространства добавляет систему факторов, отписывающих формы солидарности населения в их связи с конкретной территорией, которые позволяют анализировать состояние общинных традиций и прогнозировать «возможность создания демократического народного самоуправления» [Солженицын 1998: 187-192].

В частности, муниципальная страта публичной власти обобщенно и целостно будет описываться комплексом характеристик, таких как:

1) группа характеристик, отражающих состояние системы отношений «местное сообщество - институты местной власти», в т.ч.:

a) отношения «община - структуры общинной самоорганизации» для поддержания правопорядка («губной староста», «квартальный» и т.п. [Голованова 2016: 56]);

б) отношения «гражданское общество - институты муниципальной власти», В Т.Ч.:

- отношения «класс трудящихся - институт местных Советов» (применительно с ситуации в СССР); 
- отношения «местный электорат - местные институты представительной власти»;

- отношения «гражданское общество - местные институты прямой демократии» [Гончаров 2020] и т.п.;

2) группа характеристик, отражающих состояние системы связи «общинной» солидарности [Шмидт-Йорциг 1977: 35] муниципального населения со «своей» территорией, в т.ч.:

а) «трагедия общины» [Остром 2010: 10];

б) связь через идентичность и коллективную социально-историческую память;

в) связь малого, среднего предпринимательства на местном рынке товаров и услуг;

г) связь через «ресурсы общего пользования» (Э. Остром);

д) связь через солидарность в структуре/институции местной самоорганизации и т.п.;

3) группа характеристик, отражающих состояние системы связей гражданской солидарности населения с административной территорией муниципалитета, в т.ч.:

а) связь через избирательные участки и округа;

б) связь через собственность на землю или на другие объекты недвижимости на территории муниципалитета;

в) связь через судебную юрисдикцию;

г) связь через систему регистрации места проживания;

д) связь через регистрацию юридического адреса бизнеса;

е) связь через налоговую юрисдикцию и т.п.;

4) группа характеристик, отражающих состояние системы отношений различных общественно-политических институтов в административно-территориальных границах муниципальной территории, в т.ч.:

а) отношения «общинные структуры - институты МСУ»;

б) отношения «институты МСУ - институты государственной власти»;

в) отношения «общинные структуры - институты гражданского общества»;

г) «общинные структуры - институты государственной власти»;

д) отношения между ветвями муниципальной власти;

е) отношения «местные институты гражданского общества - институты власти МСУ»;

ж) отношения «местные институты гражданского общества - институты государственной власти» в границах муниципальной территории»;

3) отношения «местные институты гражданского общества - иные институты гражданского общества», в т.ч.:

- «местные институты гражданского общества - региональные институты гражданского общества»;

- «местные институты гражданского общества - общегосударственные институты гражданского общества»;

- «местные институты гражданского общества - иностранные институты гражданского общества».

Вопрос взаимосвязи институциональных и субъектных характеристик муниципальной публичной власти дифференцируется по четырем аспектам, которые позволяют более детально анализировать «атомарные» элементы этого топологического уровня региональной стратификации власти. Группа характеристик системы отношений «местное сообщество - институты местной власти» акцентирует внимание на субъектной активности местных общин и гражданских сообществ, от которых зависит уровень развития соответствую- 
щих институций их самоорганизации. Группа характеристик системы связи «общинной» солидарности муниципального населения со «своей» территорией также фокусируется на той части субъектных качеств местных сообществ, активность которых усиливает заботу о «своей» территории, мобилизует на поиск решений по возникающим проблемам, равно как и на защиту «своей» территории от внешних, не согласованных с населением воздействий. Эти качества в настоящее время востребованы в рамках государственной программы «Формирование комфортной городской среды». Исследования показывают, что высокий уровень активности качеств субъектности этих категорий может быть источником протестной деятельности, конфликтных отношений с властями или бизнес-девелоперами, если они стремятся сделать что-то без согласования с местным сообществом. Институциональные формы в этих регистрах муниципальной публичной власти являются производными от субъектной активности местных общин и сообществ, а также развиваются в «горизонтальных» измерениях.

Группа характеристик системы связей гражданской солидарности населения с административной территорией муниципалитета в значительной мере определяется институциональными, прежде всего правовыми, регуляторами, которые предоставляют окна возможностей для самореализации гражданских инициатив, нацелены на «активизацию участия» населения в решении вопросов местного значения, на «мобилизацию собственных материальных и трудовых ресурсов отдельных граждан», на «консолидацию граждан» в решении вопросов благоустройства населенных пунктов [Папело, Ковтун 2016: 54]. Задачи деятельности социальных институтов становятся достижимыми, если на территории есть достаточное число активных граждан, мотивированных на развитие малого или среднего бизнеса, на создание местных некоммерческих организаций, социально ориентированных НКО и т.д. Если население депрессивное, то институты деловой активности, как коммерческие, так и некоммерческие, работать на этой территории не будут [Кольба 2020: 64]. Показателен в этом плане и проблемный опыт внедрения социального контракта: слабая субъектная мотивация граждан сдерживает эффективность института социального контракта как инструмента преодоления бедности.

Группа характеристик системы отношений различных общественных, административных, политических институтов в административно-территориальных границах муниципальной территории фокусирует внимание прежде всего на институциональных регуляторах жизни и деятельности муниципальной страты публичной власти. Они учреждаются сверху и формируют вертикальную структуру административно-политических отношений. Субъектная активность населения муниципальной территории также имеет значение, но в этой группе характеристик первичное значение имеют именно институциональные рамки деятельности, которым должна соответствовать активность граждан, служащих, местных элит. В зоне этих факторов институциональные установления «сверху» ввели ограничения на деятельность местных политических партий (запрет на местные или региональные партии), ограничение практик прямых выборов главы муниципалитета, расширение числа каналов влияния губернаторов на деятельность систем муниципального самоуправления и пр. Случай, который отражает зависимость эффективной работы вновь созданного института МСУ от субъектных качеств местного населения, дает практика формирования института сельских старост [Майкова, Симонова 2018: 383].

Представленный комплексный анализ системы публичной власти в системе региональной стратификации политического пространства России в случае 
необходимости позволяет специально выделить аспекты, характеризующие качества «Политического режима», «политического процесса» или «потенциала государства» с тем отличием от современного применения этих концептов, что будет сохранять контур их взаимосвязи, а также контур их связи с иными значимыми моментами бытия и существования политического региона любого таксономического уровня. Так, применительно к муниципальной страте единой системы публичной власти можно отметить проблему ослабленности собственного потенциала власти МСУ, в т.ч. городов-доноров [Бородулина 2002] и сельских поселений, где отмечается дефицит финансовых, кадровых ресурсов и ослабление возможностей контроля территории [Майкова, Симонова 2021: 2-3]. В этой части власти стремятся «скоординировать деятельность всех уровней власти: муниципальной и государственной, чтобы все-таки хоть в чем-то была какая-то вертикаль, чтобы все это эффективно функционировало и в то же время не противоречило Конституции» 1 .

В аспекте анализа состояния политического режима можно отметить, что основные коллизии складываются в рамках установления нового баланса отношений региональных политических режимов (субъектов федерации) и муниципальных политических режимов, а основная тенденция - переход этих отношений с идейной установки на «автономизацию» политики МСУ от регионального политического режима на идейную установку партнерства публичной политики МСУ и политического режима субъекта федерации. Поэтому и базовый муниципальный политический процесс становится более сложным по своей внутренней структуре [Дахин, Семенов, Стрелков 2017]. Тенденция перехода отношений муниципальных и региональных политических режимов к практикам партнерства поддерживается параллельными тенденциями развития практик государственно/муниципально-частного партнерства, государственно/муниципально-гражданского партнерства, партнерства НКО с бизнесом, а также тенденцией муниципального гражданско-гражданского партнерства, в рамках которого некоммерческие объединения граждан взаимодействуют между собой и с ресурсными центрами $\mathrm{HKO}^{2}$. В результате постепенно формируются «горизонтальные» структуры муниципальной публичной власти.

В заключение можно отметить следующее.

Российская философия формирования единой системы публичной власти невозможна без концептуальной интеграции в нее современных представлений о региональной стратификации политического пространства страны. В самом общем виде это касается как системы институтов публичной власти, так и субъектов публичной власти, которые также распределены по различным уровням (кластерам) региональной стратификации отечественного политического пространства, имеют свои особенности как на уровне субъектов федерации, так и на уровне муниципалитетов. Политический транзит российской системы публичной власти связан с поиском оптимального для интересов отечественного устойчивого развития сочетания «вертикальных» и «горизонтальных» социальных, общественно-политических отношений на каждом уровне публичной власти. При этом теоретико-методологические ресурсы концепта «потенциал государства» позволяет анализировать и проектировать формализованные, институциональные и «вертикальные» отношения между уровнями

\footnotetext{
${ }^{1}$ Путин: вертикаль между местной и госвластью должна быть, но в рамках Конституции. ТАСС. Новости в России и мире. 22.10.2019. Доступ: https://tass.ru/politika/ 7027947 (проверено 07.03.2021).

2 Сеть ресурсных центров НКО Приволжского федерального округа. Доступ: https://nkopfo.ru/viewpoint/razvitie-territorij-osnova-deyatelnosti-kazhdoj-nko (проверено 09.04.2021).
} 
публичной власти, а теоретико-методологический потенциал концепта «политический режим» отличается тем, что в большей мере позволяет анализировать и проектировать «живые», слабо формализуемые «горизонтальные» отношения социально-политических субъектов. В свете концептуальных решений, связанных с понятием «потенциал государства», в предметной области будут преимущественно отношения «вертикального» подчинения институтов публичной власти разного уровня. В свете концепции политического режима предметная область будет связана преимущественно с вопросами «горизонтального» партнерства социально-политических субъектов.

Конституционные поправки 2020 г., касающиеся системы муниципального самоуправления, нацеливают на уточнение того, какие элементы отношений региональной и муниципальной публичной власти должны войти в структуру потенциала государства, регулироваться жесткими нормами вертикального соподчинения, а какие элементы этих отношений должны оставаться в поле действия мягких отношений «горизонтального» партнерства регионального и муниципального политических режимов. В последнем аспекте, как было показано выше, ключевое значение принадлежит субъектным качествам местных общин и гражданским формам инициативной самоорганизации населения муниципалитетов, в т.ч. муниципальных политических элит. Там, где забота населения о «своей» муниципальной территории будет воплощаться в формах общественных, гражданских, деловых или политических инициатив, муниципальная страта публичной власти сможет развернуть весь свой позитивный потенциал муниципалитета-драйвера. Там, где население продолжит пребывать в отчуждении от «своей» территории, от муниципальных властей, продолжит находиться в состоянии апатии и патерналистских ожиданий, муниципальная страта публичной власти не состоится, жизнь муниципалитета будет организовываться под внешним управлением региона или федерации, а статус территории застынет в состоянии «депрессивной» и «дотационной».

Поскольку активность как сущностное качество социально-политических субъектов играет определяющую роль в установлении фактического баланса отношений между различными стратами региональной стратификации отечественного политического пространства, то принципиальное значение имеет философия человека как субъекта цивилизационных, социальных и политических отношений и деятельности. В этой части приоритетной видится отечественная философская традиция понимания природы человека как субъекта бытия и существования общества В.С. Соловьева, С.Н. Булгакова, А.Ф. Лосева, Э.В. Ильенкова, И.Т. Фролова, Л.А. Зеленова, В.А. Кутырева и др. В современном мире глобальной философии ей противостоит постмодернистская философия повседневного человека-конструкта М. Хайдеггера, Э. Гуссерля, А. Щюца, П. Бергера, Н. Лумана, Д. Деннета и др. Основная проблема видится в том, чтобы вдохнуть энергию активности в отечественную традицию, новыми исследованиями обеспечить законченную целостность, устойчивость отечественной цивилизационной и философской системы человека перед лицом агрессивных потоков постмодернистской деонтологизации и деантропологизации общества, философии, системы публичной власти.

\section{Список литературы}

Бородулина Н.А. 2002. Города-доноры: опора федерального центра или источник региональных конфликтов? - Полис. Политические исследования. № 6. C. 127-142.

Букалова С.В., Меркулова К.Г. 2020. «Демократия малых пространств»: 
эволюция института местного самоуправления в России в контексте идей А.И. Солженицина. - Власть. Т. 28. № 4. С. 73-79.

Гайворонский Ю.О. 2015. Региональные политические режимы: концептуальные новации и возможные изменения. - Полития. № 2(77). С. 21-37.

Глазьев С.Ю. 2017. Гэлбрейт: возвращение (под ред. С. Д. Бодрунова). 2017. М.: Культурная революция. 424 с. - Социс. Социологические исследования. № 10(402). С. 165-169.

Голованова Т.В. 2016. Муниципальная милиция в России, есть ли шанс? Политика, государство, право. № 4(52). С. 55-61.

Гончаров В.В. 2020. Проблемы и перспективы закрепления и реализации в российском законодательстве форм прямой демократии на муниципальном уровне. - Вестник Полоцкого государственного университета. Серия D. Экономические и юридические науки. № 13. С. 104-107.

Горшков М.К. 2016. Российский социум в условиях кризисного развития: контекстный подход. - Социс. Социологические исследования. № 12. С. 26-33.

Дахин А.В. 2009. Система власти в России в 2000-х гг. и модели политического управления регионами. - Полис. Политические исследования. № 2. С. 52-60.

Дахин А.В. 2015а. Региональная стратификация общества: глобальное и локальное в культуре, экономике, и политике. Часть 1. - Власть. № 10. С. 5-15.

Дахин А.В. 2015б. Региональная стратификация общества: глобальное и локальное в культуре, экономике, и политике. Часть 2. - Власть. № 11. С. 40-48.

Дахин А.В. 2016. Коллективная память сообщества: невидимые структуры неизвестного знания. - МЕТОД: Московский ежегодник трудов из обществоведческих дисциплин: сборник научных трудов (ред. и сост. вып. М.В. Ильин). М.: ИНИОН РАН. С. 198-214.

Дахин А.В. 2019. Идея социального и светского государства: феноменология конституирования в России. - Юридическая наука и практика. Вестник Нижегородской академии МВД России. № 1(45). С. 274-278.

Дахин А.В., Распопов Н.П. 1998. Проблема региональной стратификации в России. - Полис. Политические исследования. № 4. С. 132-144.

Дахин А.В., Семенов Е.Е., Стрелков Д.Г. 2017. Нижегородская область в ситуации конфликта элит: основные тенденции, прогнозные гипотезы, оценки. Региональная политика. 2016: сборник статей и аналитических докладов (под ред. Д. Орлова). М.: Грифон. С. 235-244.

Жилина С. Б. 2006. Правовое обеспечение исполнения коммерческими банками публичных функций в Российской Федерации: автореф. дис. ... К.ю.н. Ростов н/Д. $28 \mathrm{c}$.

Зорькин В.Д. 2019. Право метамодерна: постановка проблемы. - Журнал конституционного правосудия. № 4(70). С. 1-8.

Киреев А.А. 2014. Понятие «регион» и предметно-методологические проблемы регионоведения. - Регионалистика. Т. 1. № 1. С. 18-32.

Кольба А.И. 2020. Исследование региональных и городских политических конфликтов: основные концепты и перспективы развития субдисциплин. Политическая наука. № 3. С. 52-73.

Круглый стол «Изменения в Конституцию РФ и публичная политика». 27 февраля 2020 г. - Публичная политика. Т. 4. № 1. С. 9-42.

Кутырев В.А., Слюсарев В.В., Хусяинов Т.М. 2020. Человечество и Технос: философия коэволюции. СПб: Алетейя. 260 с.

Майкова Э.Ю., Симонова Е.В. 2018. Формирование института сельских старост как фактор устойчивого развития российских муниципальных образований. - ХХІ Уральские социологические чтения. Социальное пространство и время региона: проблемы устойчивого развития: материалы международной научно- 
практической конференции. Екатеринбург, 15-16 марта 2018 г. Екатеринбург: Гуманитарный университет. С. 381-385.

Майкова Э.Ю., Симонова Е.В. 2021. Потенциал развития института сельских старост в современных российских муниципалитетах (на примере социологических исследований в Тверской области). - Социодинамика. № 1. С. 1-15.

Макаренко Е.И. 2020. Субъектность отечественной технической интеллигенции в осуществлении задач информатизации. - Власть. Т. 28. № 3. С. 158-163.

Михеев В.А. 2005. Социальное партнерство и пути совершенствования публичной политики. - Власть. № 7. С. 13-19.

Остром Э. 2010. Управляя общим: эволюция институтов коллективной деятельности (пер. с англ.). М.: ИРИСЭН; Мысль. 447 с.

Папело В.Н., Ковтун Б.А. 2016. Развитие института сельских старост в России: проблемы и пути решения. - East European Scientific Journal. № 14. C. 52-55.

Покида А.Н., Зыбуновская Н.В. 2020. Самозанятые граждане и социальные гарантии. - Власть. Т. 28. № 3. С. 165-172.

Прокофьева Л., Корчагина И., Миронова А., Тарновская Е. 2015. Социальный контракт как механизм преодоления бедности в России. - Журнал исследований социальной политики. Т. 13. № 1. С. 81-96.

Рувинский Р.3. 2020. Правопорядок в период глобального кризиса: трансформации, тендениии, угрозы. СПб: Алетейя. 350 с.

Советов И.К. 2020. Публичная власть в России по Конституции 2020 года. Вестник Прикамского социального института. № 3(87). С. 43-52.

Солженицын А. 1998. Россия в обвале. М.: Русский путь. 203 с.

Сунгуров А.Ю. 2006. Публичная политика как поле взаимодействия и как процесс принятия решений. - Публичная политика. № 1(1). С. 7-15.

Туровский Р.Ф. 2009. Региональные политические режимы в России: к методологии анализа. - Полис. Политические исследования. № 2. С. 77-79.

Чепьюк О.Р. 2021. Экономическая бессубъектность как фактор дегуманизации социальных отношений: дис. ... д.филос.н. Н. Новгород. 371 с.

Шатилов А.Б. 2020. «Моральный износ» власти как фактор дестабилизации политических режимов». - Власть. Т. 28. № 4. С. 9-16.

Шмидт-Йорциг Э. 1977. Финансы общин и местная хозяйственная деятельность в Германии. М.: Фонд Ф. Наумана. № 4. С. 35-42.

Busygina I. 2016. Putin's Russia: The State-Building Strategy. - Russian Politics. Vol. 1. Is. 1. P. 70-94.

Croissant A., Hellman O. 2018. Introduction. State Capacity and Elections in the Study of Authoritarian Regimes. - International Political Science Review. Vol. 39. No. 1. P. 3-16.

Dahl R.A. 1971. Polyarchy: Participation and Opposition. New Haven, CT: Yale University Press. 257 p.

Gel'man V. 2008. Out of the Frying Pan, into the Fire? Post-Soviet Regime Changes in Comparative Perspective. - International Political Science Review. Vol. 29. No. 2. P. 157-180.

Skocpol T. 1985. Bringing the State Back In: Strategies of Analysis in Current Research. - Bringing the State Back In. (ed. by P.B. Evans, D. Rueschemeyer, T. Skocpol). Cambridge: Cambridge University Press. 1985. Pp.3-43.

White D. 2018. State Capacity and Regime Resilience in Putin's Russia. International Political Science Review. Vol. 39. No. 1. P. 130-143. 
DAKHIN Andrey Vasil'evich, Dr.Sci. (Philos.), Professor of the Chair of History and Theory of State and Law, Nizhny Novgorod Institute of Management - Branch of Russian Presidential Academy of National Economy and Public Administration (46 Gagarina Ave, Nizhny Novgorod, Russia, 603950;nn9222@rambler.ru)

BALUEVA Irina Vladimirovna, Deputy Assistant of the Legislative Duma of Nizhny Novgorod (apart. 398, 4 Volodarskogo St, Nizhny Novgorod, Russia, 603006; irina_balu@mail.ru)

DAVYDOV Sergey Vladimirovich, Deputy Assistant of the Legislative Council of Nizhny Novgorod Region, postgraduate student at the Chair of Philosophy, Sociology and Psychology of Management, Nizhny Novgorod Institute of Management - Branch of Russian Presidential Academy of National Economy and Public Administration (46 Gagarina Ave, Nizhny Novgorod, Russia,603950; 537395@mail.ru)

SHCHETININA Ol'ga Vladimirovna, Vice-Chairman of the Legislative Council of Nizhny Novgorod Region, postgraduate student at the Chair of Philosophy, Sociology and Psychology of Management, Nizhny Novgorod Institute of Management - Branch of Russian Presidential Academy of National Economy and Public Administration (46 Gagarina Ave, Nizhny Novgorod, Russia, 603950; Lmakarova.zsno@yandex.ru)

\title{
THE PUBLIC POWER SYSTEM AND RUSSIA'S REGIONAL STRATIFICATION OF THE POLITICAL SPACE: INSTITUTIONS IN SEARCH OF A SOCIAL SUBJECT
}

\begin{abstract}
The article focuses on philosophical and interdisciplinary dimensions of forming the complete system of public power in Russia. Based on a comprehensive analysis of the concepts of political regime, political process, state capacities the authors propose the philosophy of its integrity into the conceptual framework of regional stratification of political space in Russia. On the example of the municipal level of the public power system they show the nature of the relationship between these concepts, as well as the possibilities of a new approach to analyze the role of municipal institutes and the role of municipal social subjects for developing the complete public power system and for prospective analysis of "vertical" "horizontal" social and political relations, studying contemporary trends. In conclusion, the authors define the basic value of philosophical elaboration of the nature of the complete public power system regarding to the feature of regional stratification of political space in Russia. In addition, the authors underline the request for elaboration of the domestic philosophy of man as a subject of civilizational, social and political development.
\end{abstract}

Keywords: complete public power system, Russia, regional stratification of political space, social institute, social subject, political regime, state capacities, municipal public power 